\title{
Army Amputees from the Falklands-Review
}

\author{
Maj A F G Groom \\ FRCS, RAMC \\ Brig J T Coull \\ FRCS, L/RAMC \\ Queen Elizabeth Military Hospital, Woolwich
}

Two years after the war in the South Atlantic the 23 major Army amputees out of a total of 38 Service amputees resulting from hostilities and their aftermath are reviewed. Of the total of 38 cases, 32 were major and six minor. It is noteworthy that, of the major Army amputees, $11(48 \%)$ occurred as the result of injury sustained after the cease-fire. Minor amputations have not been included. They do not, of themselves, pose the same problems of management, nor was the eventual medical grading effected in any of the four Army cases. The figures are not complete in that they do not include amputations of digits secondary to burns. The amputees present an opportunity to review the management of a small group of severely injured treated under the most difficult of circumstances.

Total casualties were 255 killed and 777 wounded. The 32 major Service amputees would, therefore, give an amputation rate of $4 \%$ but if the 11 cases wounded after the cease-fire are excluded the amputation rate falls to approximately $2.5 \%$.

Data on amputation rates from other conflicts are not readily available. Wiles ${ }^{1}$ reported an amputation rate of $3.5 \%$ among 29,000 battle casualties admitted to Middle East hospitals in one year from April 1942 to March 1943 and similarly the amputation rate in the European theatres in one US evacuation hospital for 12 months from 1944-45 was $3.7 \%^{2}$. Incidentally, in this latter group, clostridial myositis was the indication for amputation in $11 \%$ and overall mortality was $6.4 \%$. In the Falkland series no patient who survived to reach primary surgical care subsequently died and in no case was clostridial infection an indication for amputation.

Wounds of the extremities constituted $67.5 \%$ of injuries operated on by the Army surgical teams ${ }^{3}$. This is similar to the proportions encountered in a number of previous conflicts even though the nature of warfare may have differed significantly.

The distribution of amputation levels is given in Table I.

Pattern of Wounding: Table II lists the relative importance of wounding agents. It is sadly ironic that accidents during garrison duties, even excluding
Table I

Major Amputees-Army

\begin{tabular}{|c|c|}
\hline Above Knee & $7(2)$ W్ \\
\hline Through Knee & 1 \\
\hline Below Knee & $11(7)$ \\
\hline Above Elbow & 2 \\
\hline Below Elbow & $2(2)$ \\
\hline Totals & $23(11$ \\
\hline
\end{tabular}

The figures in brackets indicate those sustained af cease-fire.

Table II

Wounding Agent

Anti-personnel Mine
Mortar/Artillery
Gun Shot
Bomb
Sidewinder
Booby Trap
High Explosives

The figures in brackets indicate those sustained afte? cease-fire.

those associated with mine-field clearance, resulted in as many amputees as the bloodiest action of the war, namely the battle for Mount Longdon. It is also remarkable that anti-personnel mines were responsible for fewer amputations during hostilities than after the cease-fire, especially so since eachp battalion action involved direct assault against pre $\overline{3}$ pared defences including extensive mine fields.

Wound Management: First Aid. This was invariß ably given by comrades on the spot. Such treatment in itself was hazardous and indeed 2 cases were wounded while rendering first aid.

Wound Dressing: All cases had "shell" dressing applied. One required seven such dressings.

Tourniquets were used in only three of 12 case during hostilities. In none of those three did in 
appropriate use of a tourniquet contribute to the indications for amputation.

Evacuation: Methods were invariably improvised, often under conditions of extreme difficulty and danger. Most cases were manhandled to Regimental Aid Posts. One was dragged on a ground-sheet more than 3 kilometres. Two cases were carried similar distances on stretchers and three cases were carried by stretcher but for shorter distances. Three were moved from their site of wounding in a mine-field to a Field Surgical Unit by Volvo BV202 (an articulated, rubber tracked vehicle exerting extremely low ground pressure) and one case was transferred by landing craft direct to a surgical team. In all other cases rearward evacuation from the Regimental Aid Post was by helicopter.

Analgesia: All cases were given "on the spot" intra-muscular Omnopon (30 mg syrette). Those in whom evacuation was unavoidably delayed received two doses but two of the amputees found the analgesia totally ineffective.

Resuscitation: Anti-tetanus-All 23 cases received a tetanus toxoid booster $0.5 \mathrm{ml}$ intramuscularly during the resuscitation phase.

Antibiotics: In the first 24 hours nine cases received Benzyl Penicillin alone in accordance with normal policy whereas five received Benzyl Penicillin in combination with other Penicillins (variously Triplopen, Ampicillin, Cloaxillin and Flucloxacillin). Others received combinations including Metronidazole and one case of a known Penicillin allergy was treated with Tetracycline and later with a combination of Erythromycin and Metronidazole.

The antibiotic administration during this phase is summarised in Table III. No case had any other indication such as a penetrating abdominal injury to dictate an alternative antibiotic choice.

Intravenous Fluids: Requirements varied with the severity of wounding and the time to first surgery. There were clear differences between the group wounded during hostilities and those wounded after cease-fire and predictably the latter group required smaller volumes of intravenous fluids for resuscitation. The fluid administration is summarised in Table IV.

\section{Indication for amputation}

This is summarised in Table $\mathrm{V}$. The commonest indication (13/23) was completion of a de facto traumatic amputation.

In 12 cases the final level was the same as the level of traumatic amputation. In one case the traumatic below-knee amputation initially completed at that level was revised to through-knee. In seven
Table III Antibiotic Administration in First 24 Hours

Benzyl Penicillin

Benzyl Penicillin with other Penicillins

Benzyl Penicillin with Metronidazole

Triplopen with Metronidazole

Other Penicillins alone

Ampicillin and Metronidazole

Tetracyclin/Erythomycine with Metronidazole

Table IV

Resuscitation-Intravenous Fluid Administration

Average

Cases Requirement Range

\begin{tabular}{lllr}
\hline Hartmann's solution (litres) & 23 & 1.5 & $0.3-3$ \\
$\begin{array}{l}\text { Blood (units) } \\
\begin{array}{l}\text { Polygeline (Haemaccel) } \\
(500 \mathrm{ml})\end{array}\end{array}$ & 15 & 3.4 & $2-7$ \\
\hline
\end{tabular}

Table $\mathbf{V}$

Indications

Complete traumatic amputaticn

Gross disruption

Primary vascular damage

Secondary vascular insufficiency

cases the indication was gross disruption of bone and soft tissue and in only two cases was the indication primary vascular damage. They both involved the upper limb and although they were theoretically salvageable there was also a complete loss of the brachial plexus rendering attempts at salvage inappropriate. In only one case was secondary vascular insufficiency the indication for amputation where a gun-shot wound to the knee causing a severe compound upper tibial fracture raised the question of vascular damage. Two days later a below. knee amputation was performed, revised five days subsequently to an above-knee.

It is noteworthy that, in spite of the conditions of combat, and occasionally long delays before surgery, in no case was the indication for amputation due to the presence of clostridial or any other infection.

\section{Operative treatment}

The optimal surgical treatment is two procedures, one to perform or complete the primary amputation with wound excision and a second for delayed primary closure, either by suture or graft. This was achieved in three out of nine cases of those wounded during hostilities requiring primary amputation and in six of 11 such cases wounded after cease-fire. 
Of the remaining six occurring during hostilities, five required an early revision prior to closure and two required dressing changes with general anaesthesia. Of the remaining five occurring after cease-fire, four required early revisions. Three cases required secondary amputation after initial justifiable efforts at conservation.

Late stump revision was undertaken in only four cases and in two of these this amounted merely to trimming a bony spur. One case underwent formal stump shortening in an attempt to alleviate prosthetic discomfort but unfortunately healing was delayed and discomfort not ultimately relieved. One case elected to undergo forearm shortening to permit fitting of a functional prosthesis. Apart from these two cases the remaining 21 have opted to retain their emergency amputation stumps although prosthetic advice was sought in every case at the first consultation regarding the need for and the advisability of early refashioning.

\section{Rehabilitation}

On return to the UK all amputees were referred at the earliest possible opportunity to the Limb Fitting Centre. The service offered was exceptionally good and temporary prostheses were supplied with great speed, many within 24 hours. Only one of 12 below-knee amputees and five of eight above-knee amputees had stumps resembling the accepted standard length. Rehabilitation has, in some instances, been spectacular. Three of 12 below-knee amputees have passed the basic fitness test and a further three are likely to achieve this standard. One is still employed as a physical training instructor. Four of the BK group (including the double amputee) have been medically discharged. Predictably those discharged have been the younger, more junior soldiers for whom Army life depends almost entirely on physical skills and who have least to offer in technical or managerial roles. Among the eight above-knee amputees rehabilitation has been less dramatic and none, of course, can truly run. Six have been medically discharged. The two that have opted to con- tinue are both exceptionally motivated and fit. Both were due for promotion at the time of wounding and it appears that this may still be possible.

Of the upper limb amputees one has been dist charged. While the fitness test is the challenge for $\Rightarrow$ the lower limb amputee the annual personal weaponos? test is the problem for the upper limb amputee. Ofo the three still serving two have passed and the thirdo is likely to do so.

Amputation is a mutilating operation following devastating injury. Many authors have stressed the importance of early and continued attention topsychological factors in the treatment of amputees: This falls largely into the responsibility of the doc $\vec{w}$ tors treating the wounds and of the voluntary andes welfare organisations. The families also require considerable support.

It is easier to identify where external psychologica factors have delayed rehabilitation than where they have contributed to it. This series contains twoo distinct groups, namely those injured in battle orgin dangerous but essential tasks (eg mine-field cle \$rse ance) and those injured by other instances, such tas? the Sidewinder missile and booby trap after cease-fire.

The latter group was injured accidentally in cumstances they could not regard as worthwhine They were therefore at a psychological disadvantigeand it was reflected in subsequent performance: $\varnothing$

The need for understanding, support and informin tion to both amputee and family cannot be oझ्ष stressed. Motivation must be fostered and energ channelled away from resentment and into rehabiliz tation.

\section{REFERENCES}

1 WILES $P$ Analysis of Battle Casualties admitted Middle East Hospitals April 11942 to March 36 1943. Lancet April 22 1944; 523-525.

2 Ором B reported in Coates J B. Surgery in World War II: Orthopaedic Surgery in the European theatre of Operations.

3 JACKSON D $S$ et al. The Falklands War: Arms Field Surgical Experience. Ann Roy Coll Surg Engf $1983 ; 65: 281$. 